\title{
Early changes in left ventricular anterior wall dynamics and coordination after coronary artery
}

\section{surgery}

T W Koh, J R Pepper, D G Gibson

\begin{abstract}
Objective-To study how asynchronous left ventricular wall motion changes early after uncomplicated coronary artery surgery.

Design-A prospective study done before, and at $0.5,1$, and 3 hours after coronary artery grafting, with intraoperative transoesophageal cross sectional guided $M$ mode echocardiograms, high fidelity left ventricular pressure, and thermodilution cardiac output measurements. The extent and velocity of left ventricular anterior wall thickening were measured, along with regional work and power production. Abnormal thickness changes during the isovolumic periods were detected, and their effect on energy transfer quantified as cycle efficiency.
\end{abstract}

Setting-Tertiary referral cardiac centre. Patients-25 patients with a history of chronic stable angina, mean (SD) age 60 (9) years with three vessel coronary artery disease, undergoing uncomplicated coronary artery bypass grafting.

Results-14 patients had primary incoordination, as shown by wall thinning during isovolumic contraction and delayed onset of thickening (group A), and nine had premature thickening due to incoordination elsewhere (group B). The extent (thickening fraction $43(12) \% v 73(19) \%$ ) and velocity $(1.7(0.4) v 2.5(0.6) \mathrm{cm} / \mathrm{s})$ of thickening were reduced in group $A v$ group $B(P<0.001)$, as were regional stroke work $\left(2.2(0.8)\right.$ v $\left.3.3(0.4) \mathrm{mJ} / \mathrm{cm}^{2}\right)$ and peak power production $(19$ (5) $v 32$ (7) $\left.\mathrm{mW} / \mathrm{cm}^{2}\right), P<0.05$. In group $A$, these values all increased significantly within 30 minutes of operation. In group $B$, the extent of wall thickening and peak power production were unaffected by surgery, though cycle efficiency and regional stroke work both improved by $\mathbf{3 0}$ minutes $v$ before operation $(73(9) \% v 61(8) \%, 4.5$ $\left.(0.9) v 3.3(0.4) \mathrm{mJ} / \mathrm{cm}^{2}, P<0.01\right)$. Surgery had no consistent effect on left ventricular cavity size, shortening fraction, or cardiac output in either group.

Conclusions-Even in the absence of evidence of overt ischaemia, major disturbances of ventricular synchrony-both regional and generalised-are present in patients with a history of chronic stable angina requiring coronary artery bypass grafting. They regress within 30 minutes of revascularisation, suggesting that they are the direct result of coronary stenosis.
(Heart 1997;78:291-297)

Keywords: coronary artery surgery; coordination; left ventricular function

Regional left ventricular function may be depressed in patients with coronary artery disease even in the absence of myocardial infarction. The effects of coronary artery surgery are commonly characterised in terms of changes in the amplitude of regional wall motion ${ }^{1-4}$ or cavity compliance. ${ }^{56}$ Alterations in the time sequence of ventricular contraction, in which amplitude of wall motion may be normal, is a further important mechanism by which cardiac function may be impaired in such patients..$^{7-9}$ However, the early effects of revascularisation on regional left ventricular function have not been studied in detail.

We therefore undertook a comprehensive study of the early effects of uncomplicated coronary artery bypass grafting on left ventricular anterior wall function using transoesophageal echocardiography and simultaneous high fidelity left ventricular pressure measurements. ${ }^{10-12}$ We were particularly interested in the disturbances of regional myocardial work, power production, and coordination seen in patients with a history of chronic stable angina in the absence of overt ischaemia, and in the effects of coronary bypass surgery on these variables.

\section{Methods}

PATIENTS

We studied 25 patients (mean (SD) age 60 (9) years; 15 men, 10 women) undergoing routine coronary artery bypass grafting for chronic stable angina. All had stenoses of more than $70 \%$ in all three epicardial coronary arteries. Left ventricular ejection fraction measured by contrast angiography in the right anterior oblique view was $63(7) \%$. The left anterior descending coronary artery was grafted with left internal mammary artery, and the other coronary arteries with reversed saphenous vein in all cases. Three patients had old inferior myocardial infarction but none had evidence of anterior myocardial infarction, either on electrocardiography or from a wall motion abnormality on echocardiography or angiography. Five patients had inferior wall hypokinesia on angiography. Two patients were excluded because of displacement of the catheter tip manometer. The protocol was approved by the ethics committee of the Royal Brompton 


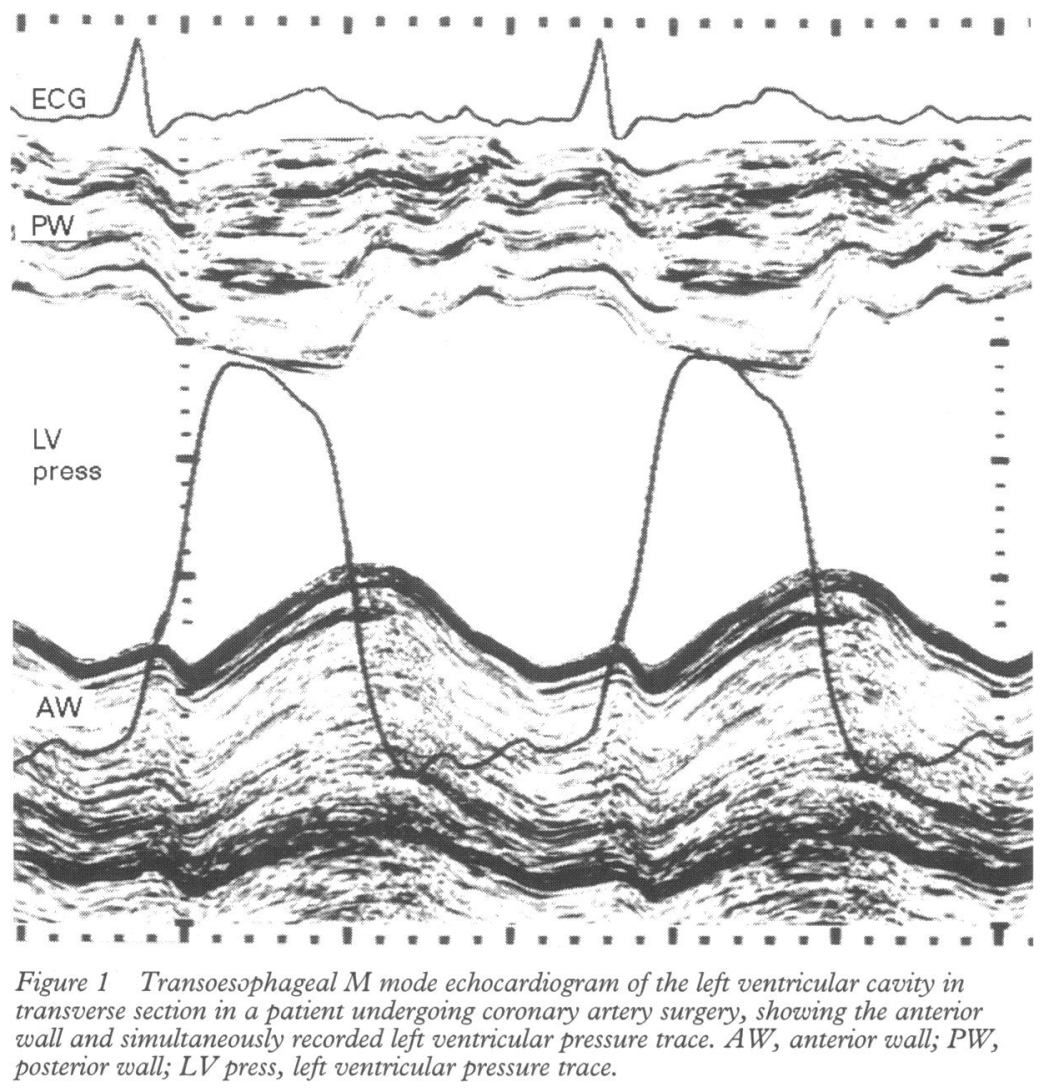

Hospital and informed consent was obtained from all patients. There were no complications during the study.

OPERATIVE PROCEDURE

The patients were operated on by the same surgeon (JRP). General anaesthesia was induced by alfentanyl and maintained with enflurane. Cardiopulmonary bypass was established with ascending aortic and single right atrial cannulation with systemic hypothermia $\left(32^{\circ} \mathrm{C}\right.$ nasopharyngeal temperature), haemodilution (packed cell volume $20-25 \%$ ), perfusion flow rate between $1.6 \mathrm{1} / \mathrm{min} / \mathrm{m}^{2}$ at $32^{\circ} \mathrm{C}$ and $2.21 / \mathrm{min} / \mathrm{m}^{2}$ at $37^{\circ} \mathrm{C}$. Antegrade and retrograde cold blood cardioplegia was used for myocardial protection. The patients were maintained on continuous sedation using intravenous propofol for at least three hours after release of the aortic cross clamp.

\section{PROTOCOL}

A $5 \mathrm{MHz}$ biplane transoesophageal probe was inserted after induction of anaesthesia and connected to a Hewlett Packard Sonos 500 echocardiographic system. A pulmonary artery catheter was inserted and cardiac output measured by thermodilution. After pericardectomy a $4 \mathrm{~F}$ catheter tip manometer was inserted into the left ventricular cavity through the roof of the left atrium, having first been passed through the chest wall at a site just above the manubrium. The output was filtered $(1 \mathrm{kHz})$, preamplified, and transferred to the auxiliary channel of the echocardiographic system. Electrical calibration of the pressure transducer was performed before initial measurement and was checked with an air operated dead weight balance (Budenberg Gauge
Company, Altringham, Cheshire, England) after the study. The zero point was taken as atmospheric pressure. After the study, the catheter tip manometer was removed by withdrawing it through its exit site in the suprasternal notch.

With the transoesophageal transducer, a transgastric view of the left ventricular cavity in transverse section was obtained and $M$ mode recordings of the left ventricular cavity at papillary muscle level made simultaneously with left ventricular pressure trace (fig 1). All recordings were made at paper speed of 100 $\mathrm{mm} / \mathrm{s}$. All measurements were made when the patient was in a stable condition at the following times: before bypass, and $0.5,1$, and 3 hours after cross clamp release. The presence of regional wall motion abnormalities or mitral regurgitation on colour flow mapping was also noted in the four chamber view. The transoesophageal probe was left in situ from the time of insertion until the final recording. After the study, sedation was discontinued and the patients were weaned off the ventilator.

The endocardial and epicardial boundaries of the anterior and posterior wall of the $M$ mode echograms were digitised offline, together with the left ventricular pressure trace. The digitising system had a sampling rate of $100 / \mathrm{s}$ and three cardiac cycles were digitised. For measurements of left ventricular dimensions, the onset of the $Q$ wave of the electrocardiogram was taken as left ventricular end diastole, and end systole was taken as the point of maximum rate of decline of left ventricular pressure. ${ }^{13}$ Left ventricular pressurewall thickness loops were constructed using a computer software program. The following were calculated: end diastolic and end systolic wall thickness, peak wall thickening and wall thinning velocities, and thickening fraction. The area of the left ventricular pressure wall thickness loop was taken as an index of regional external work, expressed in $\mathrm{mJ} / \mathrm{cm}^{2}$ of endocardium..$^{14}$ Myocardial power was derived from the product of instantaneous thickening velocity and pressure, expressed in $\mathrm{mW} / \mathrm{cm}^{2}$ of endocardium and plotted continuously. Cycle efficiency, calculated from the ratio of the left ventricular pressure loop area to the area of the rectangle which encloses it and expressed as a percentage, represents the ratio of the useful external work done to the maximum possible by myocardium working over the same range of pressure and wall thickness. ${ }^{10-12}$

Haemodynamic measurements including heart rate, peak systolic blood pressure, pulmonary artery wedge pressure, cardiac output, left ventricular stroke volume index, and left ventricular stroke work index, were also recorded.

\section{STATISTICAL ANALYSIS}

Results are presented as mean (SD). A one way analysis of variance with respect to time was performed for each variable. If a significant effect was demonstrated, variables at individual time points were compared using paired $t$ tests. We used unpaired $t$ tests to compare differences between groups. The $\chi^{2}$ test 
Table 1 Haemodynamic data. Values are means (SD)

\begin{tabular}{lclll}
\hline & Before & \multicolumn{3}{l}{ After surgery } \\
\cline { 3 - 5 } Variable & surgery & $0.5 h$ & $1 h$ & $3 h$ \\
\hline Heart rate (beats/min) & $76(13)$ & $82(10)$ & $79(8)$ & $82(9)$ \\
Mean systolic BP $(\mathrm{mm} \mathrm{Hg})$ & $100(24)$ & $93(14)$ & $92(14)$ & $95(12)$ \\
PCWP $(\mathrm{mm} \mathrm{Hg})$ & $12(4)$ & $11(3)$ & $12(3)$ & $11(4)$ \\
CI $\left(1 / \mathrm{min} / \mathrm{m}^{2}\right)$ & $2 \cdot 1(0 \cdot 4)$ & $2 \cdot 5(0 \cdot 4)$ & $2 \cdot 5(0 \cdot 4)$ & $2 \cdot 4(0 \cdot 5)$ \\
LVSVI $\left(\mathrm{ml} / \mathrm{min}^{2} / \mathrm{m}^{2}\right)$ & $28(8)$ & $31(6)$ & $31(10)$ & $29(6)$ \\
LVSWI $\left(\mathrm{g} \cdot \mathrm{m} / \mathrm{m}^{2}\right)$ & $34(7)$ & $34(8)$ & $33(6)$ & $33(6)$ \\
\hline
\end{tabular}

BP, blood pressure; CI, cardiac index; PCWP, pulmonary capillary wedge pressure; LVSVI, left ventricular stroke volume index; LVSWI, left ventricular stroke-work index.

Table 2 Echocardiographic data for left ventricular cavity and anterior wall. Values are means (SD)

\begin{tabular}{|c|c|c|c|c|}
\hline \multirow[b]{2}{*}{ Variable } & \multirow{2}{*}{$\begin{array}{l}\text { Before } \\
\text { surgery }\end{array}$} & \multicolumn{3}{|c|}{ After surgery } \\
\hline & & $0.5 h$ & $1 \mathrm{~h}$ & $3 h$ \\
\hline LVEDD $(\mathrm{cm})$ & $4 \cdot 4(0 \cdot 6)$ & $4.6(0.8)$ & $4.6(0.9)$ & $4.5(0.9)$ \\
\hline $\operatorname{LVESD}(\mathrm{cm})$ & $3.2(0.5)$ & $3 \cdot 3(0 \cdot 6)$ & $3 \cdot 2(0 \cdot 8)$ & $3 \cdot 1(0 \cdot 7)$ \\
\hline Fractional shortening (\%) & $36(5)$ & $35(5)$ & $41(7)$ & $38(7)$ \\
\hline Shortening velocity $(\mathrm{cm} / \mathrm{s})$ & $6 \cdot 8(2)$ & $9 \cdot 4(2)^{\star}$ & $9 \cdot 5(2)^{\star}$ & $8 \cdot 3(2) \dagger$ \\
\hline Lengthening velocity $(\mathrm{cm} / \mathrm{s})$ & $5.9(1)$ & $8 \cdot 2(2)^{\star}$ & $8 \cdot 2(2)^{\star}$ & $7 \cdot 3(1)^{\star}$ \\
\hline Wall thickness ED $(\mathrm{cm})$ & $1 \cdot 2(0 \cdot 2)$ & $1 \cdot 2(0 \cdot 2)$ & $1 \cdot 2(0 \cdot 2)$ & $1 \cdot 2(0 \cdot 3)$ \\
\hline Wall thickness ES (cm) & $1.6(0 \cdot 3)$ & $1.6(0.2)$ & $1.6(0.3)$ & $1.5(0.3)$ \\
\hline Thickening fraction (\%) & $55(12)$ & $57(15)$ & $62(26)$ & $57(10)$ \\
\hline
\end{tabular}

LVEDD, left ventricular end diastolic dimension; LVESD, left ventricular end systolic dimension; ED, end diastolic; ES, end systolic.

$\star P<0.01 ;+P<0.05 v$ before operation.

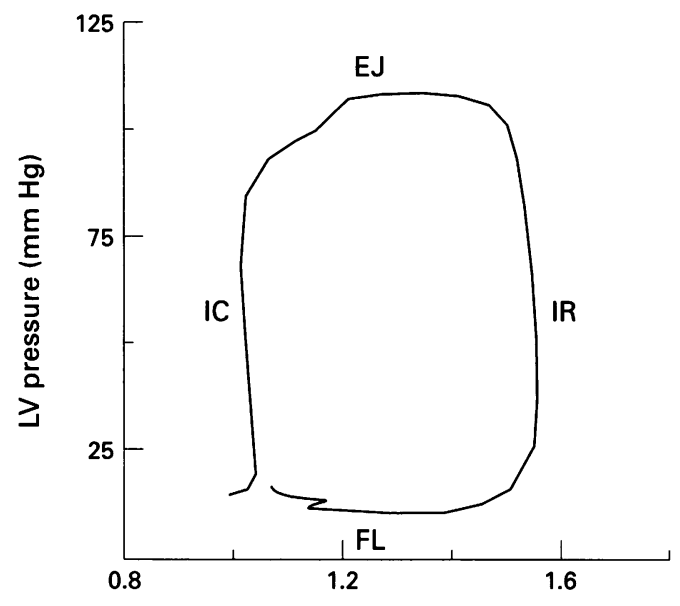

Anterior wall thickness $(\mathrm{cm})$

Figure 2 The components of a left ventricular pressurewall thickness loop are shown. The upstroke represents isovolumic contraction (IC) and the downstroke, isovolumic relaxation (IR). The sections of the loop representing ventricular ejection (E丹) and filling (FL) are also marked. A rectangular configuration, as shown, denotes coordinate anterior wall motion with wall thickness remaining constant during the isovolumic periods.

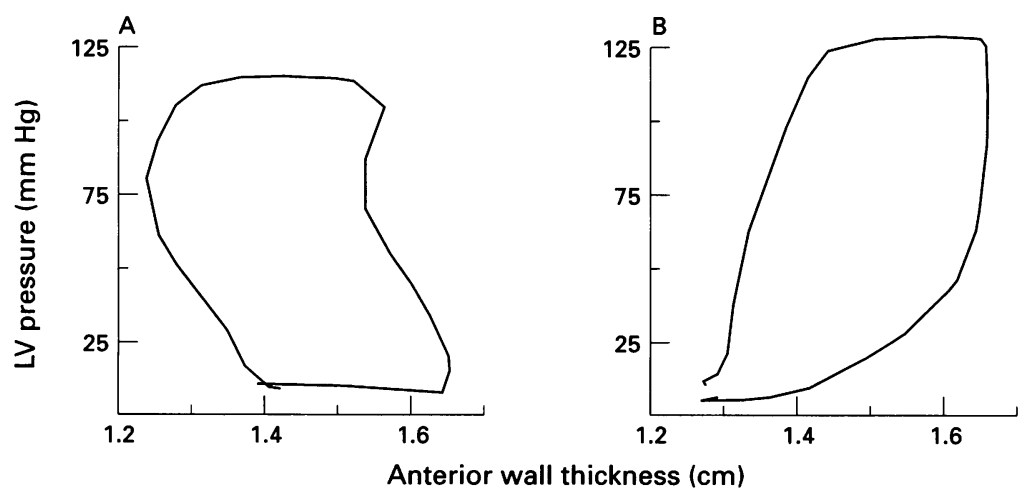

Figure 3 (A) Left ventricular (LV) pressure-wall thickness loop showing the pattern seen in group $A$ with wall thinning during isovolumic contraction and thickening during isovolumic relaxation, causing the loop to lean to the left. (B) LV pressure-wall thickness loop showing the reverse pattern seen in group $B$, with wall thickening during isovolumic contraction and concomitant thinning during isovolumic relaxation resulting in the loop leaning to the right. was used to compare non-parametric data between groups. A P value of less than 0.05 was considered significant.

REPRODUCIBILITY

Reproducibility was assessed by redigitising traces from a random sample of $10 \%$ of the beats after a period of three to six months. The variables assessed include wall thickness, thickening and thinning velocities, left ventricular end diastolic and end systolic dimensions, and cycle efficiency. The root mean square difference between duplicate measurements and the values for coefficient of variation derived from the ratio of the root mean square difference and absolute value were determined.

\section{Results}

Full revascularisation was performed in all patients. The left anterior descending coronary artery was grafted with the left internal mammary artery as a pedicle graft in all cases. No patient required either inotropic support or pacing postoperatively. Mitral regurgitation was not detected on colour flow mapping preor postoperatively in any of the patients studied. There were no new regional wall motion abnormalities in the anterior, lateral, or inferior walls after operation, as assessed from the four chamber and transgastric views. There was no evidence of intraoperative myocardial infarction in any patient on the basis of electrocardiography or creatine kinase levels. Major conduction abnormalities were not detected on the monitoring electrocardiogram in any patient.

\section{HAEMODYNAMIC DATA, LEFT VENTRICULAR AND ANTERIOR WALL ECHOCARDIOGRAPHIC VARIABLES}

Heart rate, mean systolic blood pressure, and pulmonary capillary wedge pressure did not change significantly after operation. Cardiac index, left ventricular stroke volume, and left ventricular work index were also unchanged throughout the study (table 1), and the same applied to ventricular end diastolic and end systolic dimensions and fractional shortening (table 2). However, peak shortening velocity increased at 0.5 hours $(9.4(2) \mathrm{cm} / \mathrm{s})$ and was sustained at 3 hours $(8.3(2) \mathrm{cm} / \mathrm{s})$ compared to the value before operation $(6.8(2) \mathrm{cm} / \mathrm{s}, \mathrm{P}$ $<0.05)$. Peak lengthening velocity also increased after operation at $0 \cdot 5,1$, and 3 hours (8.2 (2), $8 \cdot 2(2), 7 \cdot 3(1) \mathrm{cm} / \mathrm{s})$ compared to the value before operation $(5.9$ (1) $\mathrm{cm} / \mathrm{s}, \mathrm{P}<$ 0.001 ), though left ventricular anterior wall end diastolic and end systolic thickness values were unchanged at $0 \cdot 5,1$, or 3 hours.

\section{LEFT VENTRICULAR ANTERIOR WALI}

THICKENING AND THINNING DURING ISOVOLUMIC CONTRACTION

The initial rapid rise in left ventricular pressure from its end diastolic value occurs during isovolumic contraction and is normally not associated with a significant change in either left ventricular dimension or wall thickness. 
Table 3 Patient characteristics of group $A$ and $B$

\begin{tabular}{|c|c|c|}
\hline Variable & $\begin{array}{l}\text { Group A } \\
(n=14)\end{array}$ & $\begin{array}{l}\text { Group B } \\
(n=9)\end{array}$ \\
\hline $\begin{array}{l}\text { Age (mean }(S D)) \text { years } \\
\text { Sex }(M / F)\end{array}$ & $\begin{array}{l}60(10) \\
10 / 4\end{array}$ & $\begin{array}{l}63(9) \\
5 / 4\end{array}$ \\
\hline $\begin{array}{l}\text { Angina grade } \\
\text { NYHA class I (\%) } \\
\text { class II (\%) } \\
\text { class III (\%) }\end{array}$ & $\begin{array}{l}3(22) \\
9(64) \\
2(14)\end{array}$ & $\begin{array}{l}3(33) \\
5(56) \\
1(11)\end{array}$ \\
\hline $\begin{array}{l}\text { Previous MI } \\
\text { Anterior (\%) } \\
\text { Inferior }(\%)\end{array}$ & $\begin{array}{l}0(0) \\
2(14)\end{array}$ & $\begin{array}{l}0(0) \\
1(11)\end{array}$ \\
\hline $\begin{array}{l}\text { Medication (\%) } \\
\beta \text { blockers } \\
\text { Calcium antagonists } \\
\text { Nitrates } \\
\text { Three vessel disease (\%) } \\
\text { Left main disease (\%) } \\
\text { LVEF (mean (SD)) \% } \\
\text { No of grafts/patient (mean (SD)) } \\
\text { Cross clamp time (mean (SD)) min } \\
\text { Bypass time (mean (SD)) min }\end{array}$ & $\begin{array}{c}11(79) \\
9(64) \\
8(57) \\
14(100) \\
2(14) \\
60(6) \\
3 \cdot 3(0 \cdot 5) \\
63(10) \\
90(14)\end{array}$ & $\begin{array}{l}7(77) \\
6(66) \\
3(33) \\
9(100) \\
1(11) \\
65(8) \\
3 \cdot 4(0 \cdot 5) \\
68(12) \\
97(17)\end{array}$ \\
\hline
\end{tabular}

NYHA, New York Heart Association; MI, myocardial infarction; LVEF, left ventricular ejection fraction.

Table 4 Left ventricular anterior wall dynamics in group $A$ and $B$ before operation. Values are means $(S D)$

\begin{tabular}{lcc}
\hline Variable & Group $A$ & Group B \\
\hline Thickening velocity, cm/s & $1 \cdot 7(0 \cdot 4) \dagger$ & $2 \cdot 8(0 \cdot 6)$ \\
Thinning velocity, cm/s & $1 \cdot 7(0 \cdot 3) \dagger$ & $2 \cdot 8(0 \cdot 7)$ \\
Thickening fraction, \% & $43(12) \dagger$ & $73(19)$ \\
Peak power, mW/cm & $19(5) \dagger$ & $32(7)$ \\
Regional work, $\mathrm{mJ} / \mathrm{cm}^{2}$ & $2 \cdot 2(0 \cdot 8)^{\star}$ & $3 \cdot 3(0 \cdot 4)$ \\
Cycle efficiency, \% & $48(12)^{\star}$ & $61(8)$ \\
\hline
\end{tabular}

$\star P<0.05 ;+P<0.005$ between groups.

Table 5 Effect of revascularisation on left ventricular anterior wall dynamics in group $A$. Values are means (SD)

\begin{tabular}{|c|c|c|c|c|}
\hline \multirow[b]{2}{*}{ Variable } & \multirow{2}{*}{$\begin{array}{l}\text { Before } \\
\text { surgery }\end{array}$} & \multicolumn{3}{|l|}{ After surgery } \\
\hline & & $0.5 h$ & $1 \mathrm{~h}$ & $3 h$ \\
\hline Thickening velocity, $\mathrm{cm} / \mathrm{s}$ & $1.7(0.4)$ & $3.2(0.5)^{\star}$ & $3.2(0.9)^{\star}$ & $3.0(0.5)^{\star}$ \\
\hline Thinning velocity, $\mathrm{cm} / \mathrm{s}$ & $1.7(0.3)$ & $3.0(0.6)^{\star}$ & $3.3(1.0)^{\star}$ & $3.0(1.0)$ * \\
\hline Thickening fraction, $\%$ & $43(12)$ & $56(10)^{\star}$ & $58(13)^{\star}$ & $54(12)^{\star}$ \\
\hline Peak power, $\mathrm{mW} / \mathrm{cm}^{2}$ & $19(5)$ & $37(7)^{\star}$ & $36(12)^{\star}$ & $33(9)^{\star}$ \\
\hline Regional work, $\mathrm{mJ} / \mathrm{cm}^{2}$ & $2 \cdot 2(0 \cdot 8)$ & $3.7(0.6)^{\star}$ & $4.0(1 \cdot 0)^{\star}$ & $3.5(0.9)^{\star}$ \\
\hline Cycle efficiency, \% & $48(12)$ & $67(11)^{\star}$ & $72(6)^{\star}$ & $71(5)^{\star}$ \\
\hline
\end{tabular}

$\star \mathrm{P}<0.01 v$ before operation.

Table 6 Effect of revascularisation on left ventricular anterior wall dynamics in group $B$. Values are means (SD)

\begin{tabular}{|c|c|c|c|c|}
\hline \multirow[b]{2}{*}{ Variable } & \multirow{2}{*}{$\begin{array}{l}\text { Before } \\
\text { surgery }\end{array}$} & \multicolumn{3}{|l|}{ After surgery } \\
\hline & & $0.5 h$ & $1 h$ & $3 h$ \\
\hline $\begin{array}{l}\text { Thickening velocity, } \mathrm{cm} / \mathrm{s} \\
\text { Thinning velocity, } \mathrm{cm} / \mathrm{s} \\
\text { Thickening fraction, } \% \\
\text { Peak power, mW/ } / \mathrm{cm}^{2} \\
\text { Regional work, } \mathrm{mJ} / \mathrm{cm}^{2} \\
\text { Cycle efficiency, } \%\end{array}$ & $\begin{array}{l}2 \cdot 8(0 \cdot 6) \\
2 \cdot 8(0 \cdot 7) \\
73(19) \\
32(7) \\
3 \cdot 3(0 \cdot 4) \\
61(8)\end{array}$ & $\begin{array}{l}3.0(0.9) \\
2 \cdot 9(0.9) \\
60(20) \\
40(11) \\
4.5(0 \cdot 9)^{\star} \\
73(9)^{\star}\end{array}$ & $\begin{array}{l}3 \cdot 2(0 \cdot 9) \\
3 \cdot 1(0 \cdot 8) \\
68(17) \\
38(13) \\
4 \cdot 5(1 \cdot 0)^{\star} \\
76(7)^{\star}\end{array}$ & $\begin{array}{c}3 \cdot 2(1 \cdot 0) \\
2 \cdot 9(0 \cdot 4) \\
59(12) \\
38(11) \\
4 \cdot 1(1 \cdot 0)^{\star} \\
73(6)^{\star}\end{array}$ \\
\hline
\end{tabular}

${ }^{\star} \mathrm{P}<0.01 v$ before operation (group B), anterior wall thickening began prematurely during isovolumic contraction (fig 3B), causing the upstroke of the loop to lean to the right. Abnormal motion during the isovolumic contraction period was almost always accompanied by reciprocal abnormalities in the isovolumic relaxation period. Thus when onset of thickening is delayed in those patients with wall thinning during isovolumic contraction (group A), all except two-in whom this was the sole abnormality-also showed concomitant thickening during isovolumic relaxation due to delayed thinning. Similarly, in the nine patients with premature wall thickening during isovolumic contraction (group B) all showed premature wall thinning during isovolumic relaxation.

Table 3 summarises the patient characteristics in groups $\mathbf{A}$ and $\mathbf{B}$. There was no difference in clinical variables (age, sex distribution, angina grade, or the presence of inferior myocardial infarction) between the two groups. No patient had previous anterior myocardial infarction. Preoperative treatment with $\beta$ blockers, calcium antagonists, and nitrates was similar in the two groups. The extent of coronary artery disease was the same for both groups, assessed both from the number of vessels involved and the number of grafts necessary for complete revascularisation. Left ventricular ejection fraction from contrast angiography was similar for the two groups, with no evidence of anterior wall damage in any patient, though three patients in group A and two in group B had inferior wall hypokinesia. Cross clamp and bypass times did not differ between the groups.

Apart from loop morphology, there were significant differences between group $A$ and group B before operation (table 4). Peak wall thickening velocity $\left(\begin{array}{lllll}1.7 & (0.4) & v & 2.8 & (0.6)\end{array}\right.$ $\mathrm{cm} / \mathrm{s})$, peak thinning velocity $(1.7(0.3) v 2.8$ $(0.7) \mathrm{cm} / \mathrm{s})$, and thickening fraction $(43(12) \%$ $v 73(19) \%$ ) were all lower in group A than in group B $(P<0.005$ for all). Peak myocardial power (19 (5) $\left.v 32(7) \mathrm{mW} / \mathrm{cm}^{2}\right)$ and regional myocardial work $(2.2(0.8)$ v $3.3(0.4) \mathrm{mJ} /$ $\left.\mathrm{cm}^{2}, \mathrm{P}<0.05\right)$ were also lower in group $\mathrm{A}$ than in group B. This reduction in work not only reflected decreased amplitude of wall movement but also reduced coordination, with cycle efficiency in group A significantly less than in group B (48 (12) $v 61(8) \%, \mathrm{P}<$ $0 \cdot 05)$.

Therefore in the normal heart, a rectangular shaped loop is obtained when pressure and wall thicknesses are plotted against one another (fig 2). The initial upstroke of the pressure-length or pressure-thickness loop from the end diastole, representing isovolumic contraction, is approximately vertical. ${ }^{15}$ In our patients, two distinct patterns in the morphology of the pressure-thickness loops could be identified, based on whether there was abnormal thinning or thickening during the isovolumic contraction period, respectively. In 14 patients (group A), the anterior wall thinned during isovolumic contraction (fig $3 \mathrm{~A}$ ) so that the onset of thickening was delayed. This caused the upstroke of the pressure wall thickness loop to lean to the left. In nine patients
EFFECT OF REVASCULARISATION ON LEFT VENTRICULAR ANTERIOR WALL DYNAMICS In group $\mathrm{A}$, peak wall thickening $(3.2(0.5) v$ $1.7(0.4) \mathrm{cm} / \mathrm{s})$ and thinning (3.0 (0.6) $v 1.7$ $(0.3) \mathrm{cm} / \mathrm{s})$ velocities, thickening fraction $(43$ (12)\% v $56(10) \%$ ), and peak power production (37 (7) $v 19$ (5) $\mathrm{mW} / \mathrm{cm}^{2}$ ) had all increased by 0.5 hours after revascularisation ( $v$ before operation, $P<0.01$ ), and this increase was sustained at 3 hours for all these variables (table 5). By contrast, the corresponding measurements were unaffected by revascularisation in group B (table 6). was reflected in an increase in cycle efficiency
Asynchrony regressed in both groups. This 


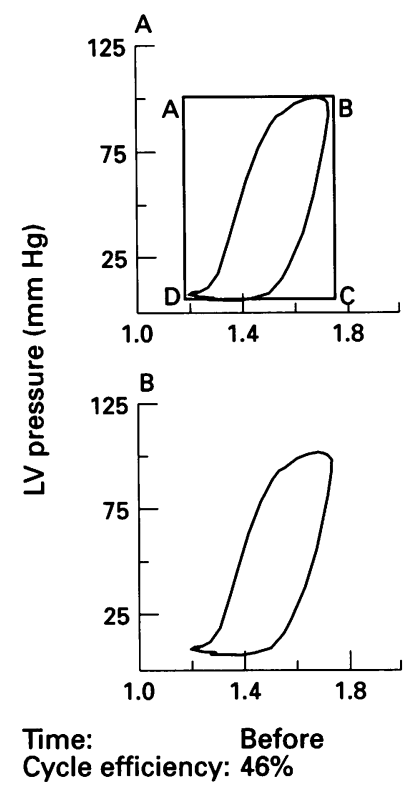

Cycle efficiency: $46 \%$

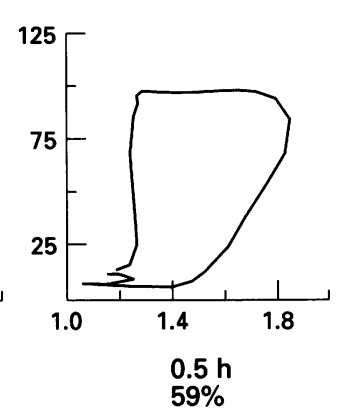

Anterior wall thickness $(\mathrm{cm})$
Figure 4 (A) Loop area represents useful work transferred to the circulation, while the area of the rectangle that just encloses it $(A B C D)$ represents the maximum possible work that could have been done over the same range of pressure and wall thickness. The ratio, expressed as a percentage is the cycle efficiency, represents the efficiency of energy transfer between the myocardium and circulation. (B) Sequence of left ventricular pressure-wall thickness loops, showing the loops becoming progressively more rectangular in configuration after revascularisation, resulting in an increase in cycle efficiency, as anterior wall resulting in an increase in cycle efficiency, as anterior wall
motion becomes more coordinate. Note that total loop area has also increased after operation.
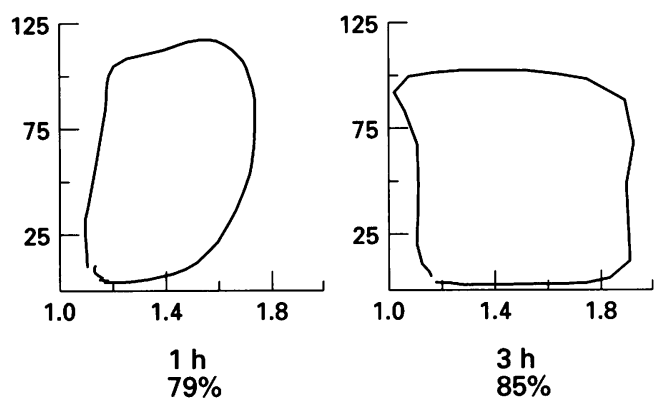

from 0.5 hours onwards in group A (67 (11)\% $v 48(12) \%)$ and group B (73 (9)\% v 61 (8)\%): $\mathrm{P}<0.01 v$ before operation (fig 4 ). As synchrony improved, so regional work increased, both in group A $(3.7(0.6) v 2.2$ $\left.(0.8) \mathrm{mJ} / \mathrm{cm}^{2}\right)$ and group B (4.5 (0.9) v 3.3 $\left.(0.4) \mathrm{mJ} / \mathrm{cm}^{2}\right)$ at 0.5 hours: $\mathrm{P}<0.01 v$ before operation. These changes after revascularisation remained significant at 3 hours. After operation, groups A and B no longer differed significantly in any of the variables measured.

\section{REPRODUCIBILITY}

The coefficient of variability of the measurements for cycle efficiency, wall thickening and thinning rates, wall thickness, and thickening fraction ranged between $3 \cdot 4 \%$ and $6 \cdot 4 \%$. Myocardial power and pressure-thickness loop area and had a variability of $7 \cdot 0 \%$ and $9 \cdot 4 \%$ respectively.

\section{Discussion}

Synchronous left ventricular contraction and relaxation is a feature of normal left ventricular function. If the time sequence of local ventricular contraction is disturbed, it can influence the function of the whole ventricle. ${ }^{7}$ Although abnormal timing may occur at any time in the cardiac cycle ${ }^{89}$ its major effects are seen when the periods of isovolumic contraction or relaxation are affected. ${ }^{10}$ In normal subjects left ventricular dimension remains almost unchanged during these two periods. A change in dimension in one part of the cavity at a time of constant volume causes a reciprocal change elsewhere, and thus a secondary change in cavity shape. This means that the effects of incoordination become generalised and are not confined to the site of the original disturbance. These changes have been studied in detail in patients with coronary artery disease by echocardiography ${ }^{16}$ and angiography. ${ }^{17-20}$ In patients with single vessel coronary artery disease, the region subtended by the diseased vessel characteristically showed prolonged inward movement and wall thickening during isovolumic relaxation. ${ }^{17}$ In the present study, we used echocardiography and simultaneous left ventricular pressure measurements to document the acute effects of uncomplicated surgical revascularisation, not only to demonstrate the time relations between the restoration of coronary flow and their resolution, but also to serve as a baseline for adopting the method as a monitoring technique in high risk patients.

The left ventricular pressure-thickness loop for the anterior wall showed major distortion in all patients undergoing revascularisation for three vessel coronary disease. In over half the patients studied (group A) there was thinning during isovolumic contraction. This thinning is the direct cause of the dimension increase during isovolumic contraction and thickening during isovolumic relaxation previously documented by echocardiography and angiography in such patients ${ }^{1617}$ Its basis is the delay in onset, due to local ischaemia, of local tension development with respect to regions with more normal function, and it thus represents a primary abnormality in the region subtended by a stenosed coronary artery.

In the remaining patients (group B) we observed secondary effects of the change in cavity shape. Here the wall thickened during isovolumic contraction and thinned during isovolumic relaxation. These changes represent the reciprocal effects in otherwise normal regions, of primary (group A) disturbances elsewhere in the ventricle at times of constant ventricular volume. ${ }^{1821}$ Although all our patients had three vessel disease, it would not be surprising if in some patients, the primary abnormality affected the anterior wall while in others it was elsewhere. Coronary artery disease influences regional function in a heterogeneous way, depending on the extent of stenoses in different vessels, the development of collateral supply, and dynamic factors that 
control myocardial oxygen supply and demand.

Our findings are also compatible with the acute study of Sasayama et al, who used pressure-length loops derived from angiography and showed that overt ischaemia induced by rapid atrial pacing produced the equivalent pattern of change in loop morphology as was shown in group A patients-segment lengthening during isovolumic contraction corresponding to wall thinning in ours. ${ }^{19}$ Our additional finding that thickening and thinning velocities, along with thickening fraction, were also reduced in this group is in line with the finding of reduced excursion shown by Sasayama et al. We conclude, therefore, that regions identified by wall thinning during isovolumic contraction have profoundly depressed function under control conditions. This represents the behaviour of myocardium supplied by a critically stenosed coronary artery. By contrast, the behaviour of segments showing wall thickening during isovolumic contraction, but where the wall dynamics are otherwise maintained (group B), is exactly what would be predicted when the primary disturbance is elsewhere in the ventricle.

When the coronary arteries are grafted, the synchrony of regional myocardial function improved within 30 minutes in all patients, whether they showed group A or group B abnormalities. Coronary artery grafting did not affect the extent of wall thickening and its systolic and diastolic rates in group B, but they consistently increased in group A. These findings are again consistent with the idea that preoperative disturbances were the direct result of coronary artery narrowing in group A, and the indirect result in group B. All our patients had stable angina preoperatively and none had electrocardiographic evidence of ischaemia at the time that the preoperative observations were made. We conclude that even without classical evidence of myocardial ischaemia, many aspects of regional myocardial function are chronically depressed in patients with stable coronary artery disease, and that these changes improve within 30 minutes of revascularisation.

Our study has limitations. The need for simultaneous transoesophageal and left ventricular pressure measurements meant that the most suitable time for introduction of the probe and catheter tip manometer was when the patient was under general anaesthetic. Though any additional direct effect of the anaesthesia on ventricular function, or effect of interaction between anaesthesia and coronary stenoses, cannot be excluded, the early regression of the abnormalities while the patient was still under anaesthesia suggests that the changes reflect improvement in myocardial blood supply as a result of coronary artery surgery. However, an interaction between anaesthesia and surgery has not been excluded. Patients served as their own controls since for obvious ethical reasons normal values are not available. With the increase in percutaneous interventional procedures for ischaemic heart disease, triple vessel disease reflects the current pattern of disease referred for surgical revascularisation, so we were unable to investigate patients with single vessel disease. We were limited in this clinical setting to leaving the probe and transducer tip catheter in situ for three hours, and therefore any later changes could not be documented. We used $M$ mode rather than cross sectional echocardiography, since our aim was to study regional function, and since its high repetition rate allows abnormalities in timing to be delineated in detail. Our patients were at low risk of adverse clinical events and the study design was therefore inappropriate to investigate whether or not there was any relation between adverse clinical outcomes and the regional abnormalities we describe. However, in patients with unstable angina or poor left ventricular function, in whom the abnormalities are more profound, such an association may occur.

In the clinical context, our results show that in a substantial proportion of patients with chronic stable angina and normal ejection fraction, and in the absence of overt ischaemia, regional myocardial function may be significantly depressed. This depression could not be consistently defined in terms of any reduction in overall amplitude of endocardial motion or wall thickening, the two measurements that form the basis of the subjective wall motion scores that are widely used to assess ventricular function in patients with coronary artery disease. The $95 \%$ normal limits of measures of amplitude are very wide, and in some regions of the ventricle include akinesis. ${ }^{22}$ In order to demonstrate depression, it was necessary to describe function objectively, in clearly defined mechanical terms. When this was done, it was apparent that regional work and power production were both substantially reduced, and that coordination-a major determinant of energy transfer from the myocardium to the circulation-was impaired both locally and in more distant regions of the ventricle. Regional myocardial tension-time development correlates well with oxygen consumption, ${ }^{23}$ so distortion of local dimension or pressure-wall thickness relations implies widespread mechanical inefficiency. ${ }^{10-12} 14$ These changes are reversed within 30 minutes of revascularisation, both locally and also in their indirect effects. It has recently become apparent that wall motion abnormalities, assessed subjectively, are common perioperatively and may have an important impact on the outcome of coronary artery surgery. ${ }^{24}$ We believe that the increased sensitivity of objective measurements such as the present ones may give clinically useful information in high risk patients. Although catheter tip manometry and offline digitisation increase the complexity of the method, we believe that this is outweighed by the sensitivity of objective measurements in detecting depressed myocardial function. They may give information of direct clinical value in higher risk patients, allowing deterioration to be detected earlier and appropriate action to be instituted more promptly, as well as assessing drugs ${ }^{25}$ or other manoeuvres 
designed to optimise myocardial protection, and monitoring patients in whom the main indication for revascularisation is to restore myocardial function rather than treat symptoms.

TWK is supported by a British Heart Foundation Junior Research Fellowship.

1 Topol EJ, Weiss JL, Guzman P, Dorsey-Lima S, Blanck TJJ, Humphrey LS, et al. Immediate improvement of dysfunctional myocardial segments after coronary revascularization: detection by intraoperative transoesophageal echocardiography. $f \mathrm{Am}$ Coll Cardiol 1984;4: phageal

2 Brundage BH, Massie BM, Botvinick EH. Improved regional ventricular function after successful surgical regional ventricular function after successful surg
revascularization. $\mathcal{F} \mathrm{Am}$ Coll Cardiol 1984;3:902-8.

3 Bolli R, Hartley CJ, Chelly JE, Patel BS, Rabinovitz RS, Jeroudi MO, et al. An accurate, non traumatic ultrasonic method to monitor myocardial wall thickening in patients undergoing cardiac surgery. $\mathcal{F} \mathrm{Am}$ Coll Cardiol 1990;15. 1055-65.

4 Dahl JV, Altehoefer C, Sheehan FH, Buechin P, Uebis R, Messmer BJ, et al. Recovery of regional left ventricula dysfunction after coronary revascularization. $₹ \mathrm{Am}$ Coll Cardiol 1996;28:948-58.

5 McKenney PA, Apstein CS, Mendes LA, Connelly GP Aldea GS, Shemin RJ, et al. Increased left ventricular diastolic chamber stiffness immediately after coronary artery bypass surgery. $7 \mathrm{Am}$ Coll Cardiol 1994;24: 1189-94.

6 Higashita R, Sugawara M, Kondoh Y, Kawai Y, Mitsui K, Ohki $S$, et al. Changes in diastolic regional stiffness of the Ont ventricle before and after coronary artery of the left ventricle before and after coron

grafting. Heart Vessels 1996;11:145-51. mawson JR, Gibson DG. Regional left ventricular wall
motion in pacing induced angina. Br Heart $₹ 1988 ; 59$ : 309-18.

8 Holman BL, Wynne J, Idoine J, Neill J. Disruption of the temporal sequence of regional ventricular contraction. Characteristics and incidence in
Circulation 1980;61:1075-83.

9 Yamagishi T, Ozaki M, Kumada T, Ikezono T, Shimizu T, Furutani $\mathrm{Y}$, et al. Asynchronous left ventricular diastolic filling in patients with isolated disease in the left anterio descending coronary artery: assessment with radionuclide ventriculography. Circulation 1984;69:933-42.

10 Gibson DG, Brown DJ. Assessment of left ventricular systolic function from simultaneous echocardiographic an pressure measurements. Br Heart $\mathcal{F}$ 1976;38:8-17.

11 Jin XY, Pepper JR, Brecker SJ, Carey JA, Gibson DG.
Early changes in left ventricular function after aortic valve replacement for isolated aortic stenosis. $A m \mathcal{f}$ Cardiol 1994;74:1142-6.

12 Hess OM, Murakami T, Krayenbuehl HP. Does verapamil improve left ventricular relaxation in patients with myocardial hypertrophy? Circulation 1986;74:530-43.

13 Abel FL. Maximal negative $\mathrm{dP} / \mathrm{dt}$ as an indicator of end systole. Am F Physiol 1962;240:H676-9.

14 Miyazaki S, Goto Y, Guth BD, Miura T, Indolfi C, Ross J. Change in regional myocardial function and external work in exercising dogs with ischemia. Am $\mathcal{f}$ Physiol 1993;264: H110-16.

15 Foëx P, Francis CM, Cutfield GR, Leone B. The pressurelength loop. Br $\mathcal{F}$ Anaesth 1988;60:65-71S.

16 Doran JH, Traill TA, Brown DI, Gibson DG. Detection of abnormal left ventricular wall movement during isovolumic contraction and early relaxation. Comparison of echo- and angiocardiography. $B r$ Heart $\mathcal{f}$ 1978;40: 367-71.

17 Gibson DG, Traill TA, Brown DJ. Changes in left ventricular free wall thickness in patients with ischaemic heart ular free wall thickness in patients

18 Gibson DG, Prewitt TA, Brown DJ. Analysis of left ventricular wall movement during isovolumic relaxation and its relation to coronary artery disease. $B r$ Heart $\mathcal{f} 1976$; its relation

19 Sasayama S, Nonogi H, Fujita M, Sakurai T, Wakabayashi A, Kawai C, et al. Analysis of asynchronous wall motion by regional pressure length loops in patients with coronary artery disease. F Am Coll Cardiol 1984;4:259-67.

20 Karliner JS, Bouchard RJ, Gault JH. Dimension changes of the human left ventricle prior to aortic valve opening. A cineangiographic study in patients with and without left heart disease. Circulation 1971;44:312-21.

21 Gaasch WH, Blaustein AS, Bing OHL. Asynchronous (segmental early) relaxation of the left ventricle. $7 \mathrm{Am} \mathrm{Coll}$ Cardiol 1985;5:891-7.

22 Pandian NG, Skorton DJ, Falsetti HL, Burke ER, Kerber RE. Heterogeneity of left ventricular segmental thickness and excursion in 2-dimensional echocardiograms of normal human subjects. Am $\mathcal{J}$ Cardiol 1983;51:1667-73.

23 Nakano K, Sugawara M, Kato T, Sasayama S, Carabello $\mathrm{BA}$, Asanoi $\mathrm{H}$, et al. Regional work of the human left venBA, Asanoi $\mathrm{H}$, et al. Regional work of the human left ventricle calculated by wall stress and the natural logarithm
of reciprocal of wall thickness. $\mathscr{f}$ Am Coll Cardiol 1988; 12:1442-8.

24 Leung JM, O'Kelly B, Browner WS, Tubau J, Hollenberg M, Mangano DT, the SPI Research Group. Prognostic importance of postbypass regional wall motion abnormalities in patients undergoing coronary artery bypass graft surgery. Anesthesiology 1989;71:16-25.

25 Boldt J, Rothe G, Schindler E, Doll C, Gorlach G, Hempelmann G. Can clonidine, enoximone and enalaprilat help to protect the myocardium agains ischaemia in cardiac surgery? Heart 1996;76:207-13. 